\title{
Corrigendum: Multisensory integration of dynamic emotional faces and voices: method for simultaneous EEG-fMRI measurements
}

\author{
Patrick D. Schelenz ${ }^{1,2 *}$, Martin Klasen ${ }^{1,2}$, Barbara Reese ${ }^{1,2}$, Christina Regenbogen ${ }^{1,2}$, \\ Dhana Wolf ${ }^{1,2}$, Yutaka Kato ${ }^{1,3}$ and Klaus Mathiak ${ }^{1,2,4}$ \\ ${ }^{1}$ Department of Psychiatry, Psychotherapy, and Psychosomatics, Medical School, Rheinisch-Westfälische Technische \\ Hochschule Aachen University, Aachen, Germany, ${ }^{2}$ Jülich Aachen Research Alliance, Translational Brain Medicine, Aachen, \\ Germany, ${ }^{3}$ Department of Neuropsychiatry, Keio University School of Medicine, Tokyo, Japan, ${ }^{4}$ Institute of Neuroscience and \\ Medicine, Forschungszentrum Jülich GmbH, Jülich, Germany
}

Keywords: emotion, audiovisual integration, emotion integration, methods for EEG-fMRI, affective neuroscience, EEG-fMRI, perceptual processing

\section{A corrigendum on}

Multisensory integration of dynamic emotional faces and voices: method for simultaneous EEG-fMRI measurements

by Schelenz, P. D., Klasen, M., Reese, B., Regenbogen, C., Wolf, D., Kato, Y., et al. (2013). Front. Hum. Neurosci. 7:729. doi: 10.3389/fnhum.2013.00729

\section{OPEN ACCESS}

Edited and reviewed by: Benjamin Kreifelts, University of Tübingen, Germany

*Correspondence: Patrick D. Schelenz pschelenz@ukaachen.de

Received: 15 November 2016 Accepted: 23 November 2016 Published: 01 December 2016

Citation:

Schelenz PD, Klasen M, Reese B, Regenbogen $C$, Wolf $D$, Kato $Y$ and Mathiak K (2016) Corrigendum: Multisensory integration of dynamic emotional faces and voices: method for simultaneous EEG-fMR measurements.

Front. Hum. Neurosci. 10:624 doi: 10.3389/fnhum.2016.00624
Reason for Corrigendum:

In the original article, a term "wrote the paper" appeared in the Author Contributions. This was unintentionally vague and did not differentiate between writing and correcting the manuscript. The authors apologize for the lack of clarity. This error does not change the scientific conclusions of the article in any way.

The corrected Author Contributions are as follows:

\section{AUTHOR CONTRIBUTIONS}

PS and MK designed the paradigm. PS collected the data and BR, MK, and DW helped acquiring the data. PS analyzed the data. YK, CR, and KM supported data analysis and interpretation. PS wrote and all co-authors corrected the manuscript. All authors gave final approval of the version to be published.

Conflict of Interest Statement: The authors declare that the research was conducted in the absence of any commercial or financial relationships that could be construed as a potential conflict of interest.

Copyright (c) 2016 Schelenz, Klasen, Reese, Regenbogen, Wolf, Kato and Mathiak. This is an open-access article distributed under the terms of the Creative Commons Attribution License (CC BY). The use, distribution or reproduction in other forums is permitted, provided the original author(s) or licensor are credited and that the original publication in this journal is cited, in accordance with accepted academic practice. No use, distribution or reproduction is permitted which does not comply with these terms 